\title{
Microscopic Laser Raman and Infrared Spectroscopic Study of
}

\section{Tengchongite}

\author{
Linfei Qiu ${ }^{1,2}$, Baoqun $\mathrm{Hu}^{{ }^{*}}$, Guang Fan ${ }^{2}$ \\ 1 State Key Laboratory Breeding of Nuclear Resource and Environment, East China University of \\ Technology, Nanchang 330013,China; qlf0602@163.com(L.Q.); \\ bqhu@ecit.edu.cn(B.H.);fangguang2008@163.com(G.F); \\ 2 Beijing Research Institute of Uranium Geology, Beijing 100029, China \\ *Correspondence: bqhu@ecit.edu.cn
}

Abstract: Tengchongite is a uranyl molybdate uranium mineral and it was found and named by Chen 1985. No more scholars studied on tengchongite after Chen's work, The identification of this mineral has only been confirmed by single crystal X-ray diffraction. In the paper, micro laser Raman spectroscopy and infrared spectroscopy are used to identify the spectroscopy properties of tengchongite. The studies fill in the gaps of more than 30 years in terms of the molecular spectroscopy research of tengchongite. The mineral has an ideal model of $\mathrm{Ca}\left(\mathrm{UO}_{2}\right)_{6}\left(\mathrm{MoO}_{4}\right)_{2} \mathrm{O}_{5} \cdot 12 \mathrm{H}_{2} \mathrm{O}$ its bands attributed to the vibrating units are clearly identified in the Raman spectrum. Symmetric stretching modes at $812 \mathrm{~cm}^{-1}$ and $839 \mathrm{~cm}^{-1}$ are assigned to $v 1\left(\mathrm{UO}_{2}\right)^{2+}$, The $v 3$ antisymmetric stretching modes of $\left(\mathrm{UO}_{2}\right)^{2+}$ are observed at $896 \mathrm{~cm}^{-1}$, Symmetric stretching modes at 419 and $440 \mathrm{~cm}^{-1}$ are assigned to $\mathrm{v} 2\left(\mathrm{UO}_{2}\right)^{2+}$. Symmetric stretching modes at $919 \mathrm{~cm}^{-1}$ are assigned to $v 1\left(\mathrm{MoO}_{4}\right)^{2-}$, The $v 3$ antisymmetric stretching modes of $\left(\mathrm{MoO}_{4}\right)^{2-}$ are observed at $752 \mathrm{~cm}^{-1}$, the in-plane $v 2\left(\mathrm{MoO}_{4}\right)^{2-}$ and the out-of-plane $v 4\left(\mathrm{MoO}_{4}\right)^{2-}$ bending modes are at $169 \mathrm{~cm}^{-1}$ and 254 $\mathrm{cm}^{-1}$. IR spectrum of tengchongite shows the major uranyl band at $858 \mathrm{~cm}^{-1}$ and $693 \mathrm{~cm}^{-1}$, Mo-O bonds are observed at about $985 \mathrm{~cm}^{-1}$ and $780 \mathrm{~cm}^{-1}$, and $\mathrm{H}_{2} \mathrm{O}$ groups are present with a wide range peaks from 3100 $\mathrm{cm}^{-1}$ to $3500 \mathrm{~cm}^{-1}$ and $1647 \mathrm{~cm}^{-1}$, and the band at $1432.4 \mathrm{~cm}^{-1}$ is probably due to the stretching vibration hydroxyl $\left(\mathrm{OH}^{-1}\right)$, therefore, tengchongite contains may include hydroxyl and its chemical formula needs to be modified .

Keywords : Tengchongite; microscopic laser Raman spectroscopy; infrared spectroscopy; Yunnan Province

\section{Introduction}

Tengchongite is a uranyl molybdate uranium mineral discovered and namedfor the first time byChen in 1985[1].It is hosted in the uranium oxidation zone between an eyeball-shaped migmatite and a schist-type migmatite in Tengchong County, Yunnan Province [2]. Naturally, tengchongite is yellow, transparent to translucent, and with glassy luster. It crystallizes in schists, thin plates, or plate along $\{001\}$ surface (Figure 1).The ideal chemical formula of tengchongite is $\mathrm{Ca}\left(\mathrm{UO}_{2}\right)_{6}\left(\mathrm{MoO}_{4}\right)_{2} \mathrm{O}_{5} \cdot 12 \mathrm{H}_{2} \mathrm{O}$. Chen et al. (1985)confirmed tengchongite as a new mineral through chemical composition, electron probe analysis, refractive index, X-ray powder diffraction, differential thermal analysis and infrared spectral( $\mathrm{KBr}$ disk method)composition of the tablet, however, no more study on 
tengchongite has been done since then. Zhang et al.(1995) and Peter C et al. (1999) cited the research results of tengchongite in their monographs[3,4]. However, the X-ray diffraction of single tengchongite crystal, and the microscopic laser Raman and infrared spectroscopy of the mineral have not been carried out yet, which leads to a lack of spectroscopy data of the tengchongite. Laser Raman and infrared spectroscopy are effective techniques for identification of minerals. In this paper, the spectroscopy of the tengchongite was supplemented.

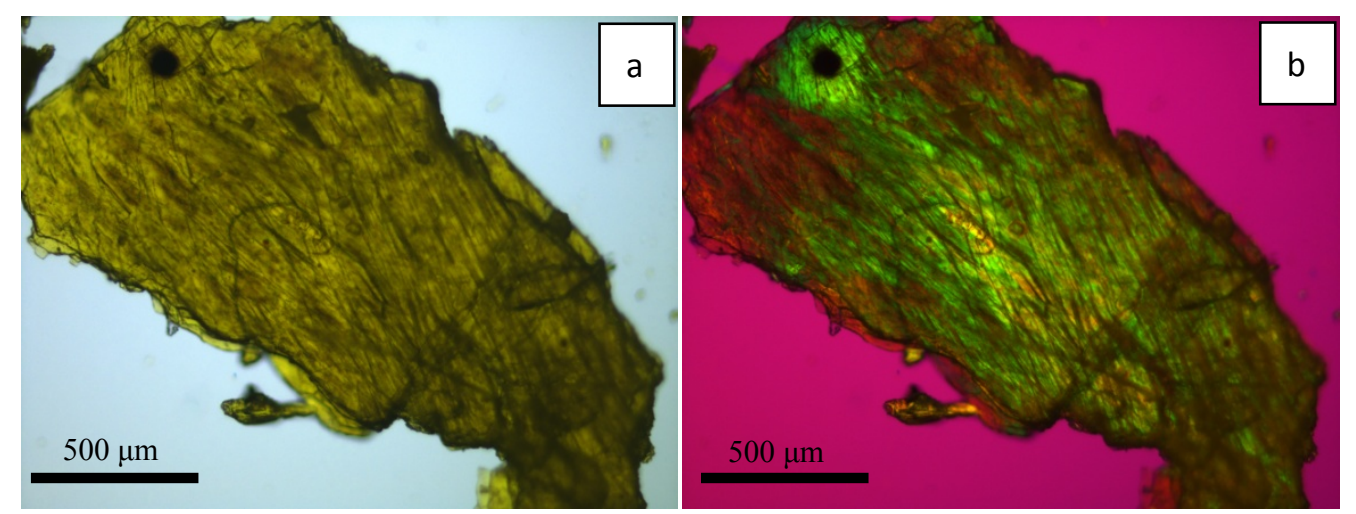

Figure1. Micrograph of tengchongite.(a)Transmission light photo of tengchongite.(b)Orthogonal polarized photo of tengchongite

\section{Samples and Analytical Methods}

\subsection{Samples}

The tengchongite sample was from the exhibition specimen in the China Nuclear Geology Museum. Before the analysis of microscopic laser-Raman and IR spectroscopy, the sample was firstly analyzed for more accurate chemical composition by EDX method.

\subsection{SEM and EDX Analysis}

Secondary electronic images and back-scattered electronic images were obtained from TESCAN VEGA3 scanning electronic microscope. The sample size is $<5 \mathrm{~mm}$. The equipment parameters are set as that: high voltage is $20 \mathrm{KV}$, beam intensity is $15 \mu \mathrm{A}$, and working distance is $15 \mathrm{~mm}$. Chemical composition was analyzed by EDAX TEAM energy dispersive spectrometer with the following parameters: single point acquisition time of $200 \mu$ s,inputCPS more than 20000, and dead time less than 30 s.

\subsection{Raman microprobe spectroscopy}

The crystals of tengchongite were placed on the stage of an Olympus BX-41microscope that is equipped with $10 \times$ to $100 \times$ objectives and a part of HORIBA evolution laser Raman microscope system, as well as an electronic cooled CCD detector, an illuminant system and a filter system. The Raman spectra were excited by 532nmand $785 \mathrm{nmYAG}$ laser at a resolution of $1 \mathrm{~cm}^{-1}$ with the following parameters: $100 \times$ objectives, scanning range between 100 and $4000 \mathrm{~cm}^{-1}$,grating of $1800 \mathrm{gr} / \mathrm{mm}$, gaining a single point in 8 seconds, accumulating for 4 times. 
Spectra were calibrated using the $520.7 \mathrm{~cm}^{-1}$ line of a silicon wafer. Data process and spectral manipulation such as smoothing, peak analyzing and baseline correcting were performed using the software Labspec 6 by Horiba Scientific.

\section{4 .Mid-IR spectroscopy}

Mid-infrared spectra were obtained using BRUKER LUMOS Micro-FTIR with in reflection model. We obtained the spectra of tengchongite after 64 scans with a scanning range between 4000 and $640 \mathrm{~cm}^{-1}$ and a resolution of $4 \mathrm{~cm}^{-1}$. Data process and spectral manipulation such as smoothing, baseline adjustment, normalization and band component analysis were performed using the special software OPTU 7.5 as an accessory of the instrument.

\section{Results and discussion}

Before analysis of microscopic laser Raman and infrared spectroscopy, the chemical composition of the sample was analyzed byTescanVega3 scanning electronic microscope and EDAX spectrometer. The electronic microscopic image, U-Mo-Ca elements EDX mapping image and spectrum analysis diagram are shown in Figure 2.The analysis results suggest that the sample is dominantly composed of $\mathrm{U}, \mathrm{Mo}, \mathrm{Ca}$, and $\mathrm{O}$, and the ratio of $\mathrm{U}$ to Mo atoms is about 3, which is in good match with the chemical composition of the Tengchongite. The EDX mapping image indicates that the elements U,Mo and Ca are uniform distributed in the sample. All evidences prove that the sample is exactly tengchongite.
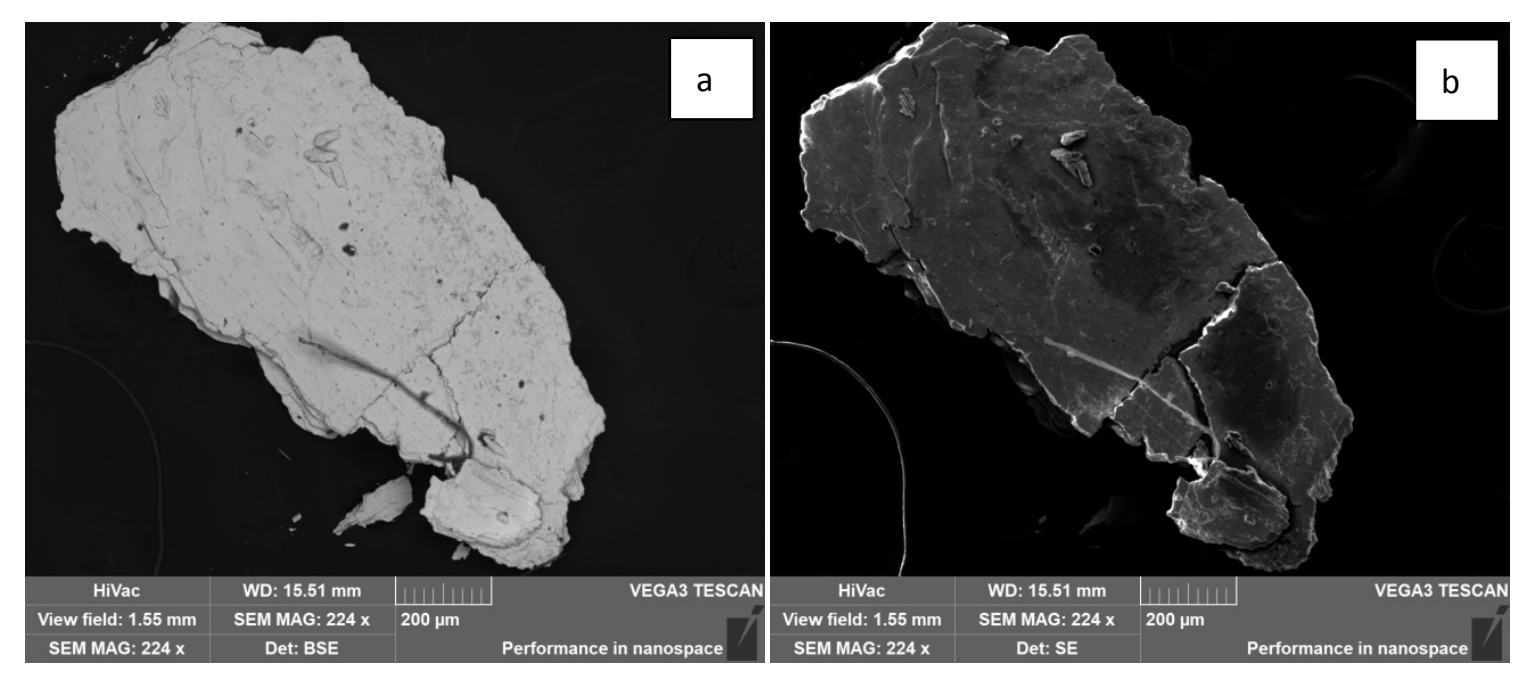

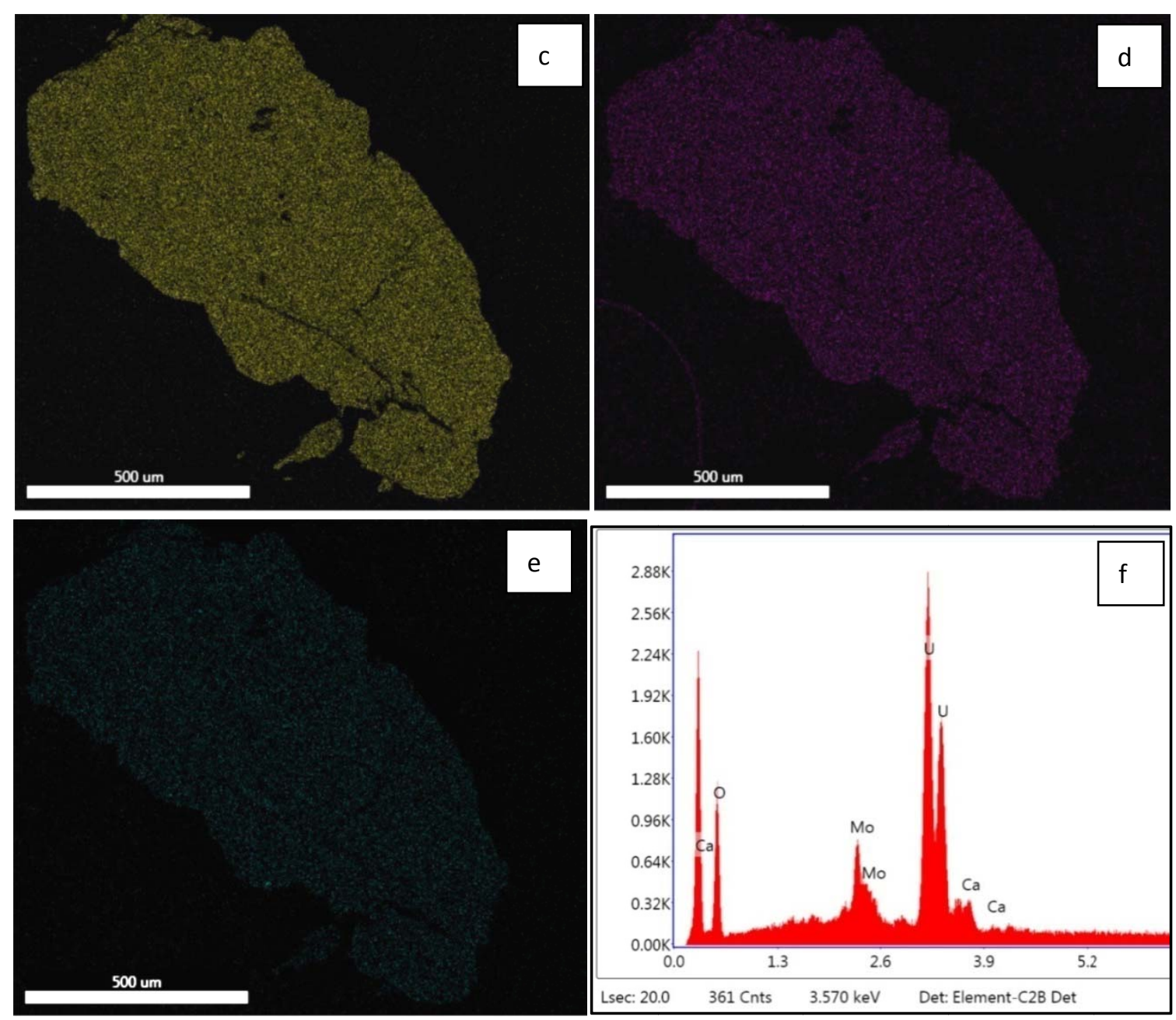

Figure 2.Electronicscanningmicroscopic image and dispersive spectrum of tengchongite

(a)Electronic scanning backscattered image;(b)Secondary electronic image; (c)EDX mapping of U; (d)EDX mapping of Mo;(e)EDX mapping of Ca; (f)dispersivespectrum of tengchongite.

\subsection{Laser Raman spectroscopy of tengchongite}

Laser Raman spectroscopy has been proven effective in the study of minerals and fluid inclusions [5-14]. There is no obvious peaks of Raman spectrum above $1000 \mathrm{~cm}^{-1}$ for tengchongite. The Raman spectrum of tengchongite within $100 \mathrm{~cm}^{-1}$ to $1400 \mathrm{~cm}^{-1}$ in the $532 \mathrm{~nm}$ and $785 \mathrm{~nm}$ models is respectively shown in Figure3. There are four strong absorption peaks and no obvious difference between the $532 \mathrm{~nm}$ and $785 \mathrm{~nm}$ models.

Raman bands at $812 \mathrm{~cm}^{-1}$ and $840 \mathrm{~cm}^{-1}$ are attributed to the $v_{1}\left(\mathrm{UO}_{2}\right)^{2+}$ symmetric stretching vibration. Raman band at $896 \mathrm{~cm}^{-1}$ is attributed to the $v_{3}\left(\mathrm{UO}_{2}\right)^{2+}$. Raman bands at $419 \mathrm{~cm}^{-1}$ and $440 \mathrm{~cm}^{-1}$ areattributed to the $v_{2}\left(\mathrm{UO}_{2}\right)^{2+}$ in-planebending modes. Raman band at $919 \mathrm{~cm}^{-1}$ isattributedto $v_{1}\left(\mathrm{MoO}_{4}\right)^{2-}$ symmetric stretching vibration. The $v_{3}$ antisymmetric

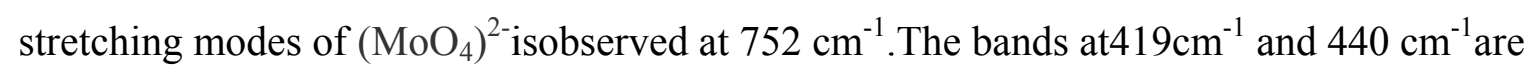
attributed to $v_{2}\left(\mathrm{MO}_{4}\right)^{2-}$ in-plane bending modes. The $v_{4}$ out-of-plane bending mode of $\left(\mathrm{MO}_{4}\right)^{2-}$ is observed at $169 \mathrm{~cm}^{-1}$ and $254 \mathrm{~cm}^{-1}$. 


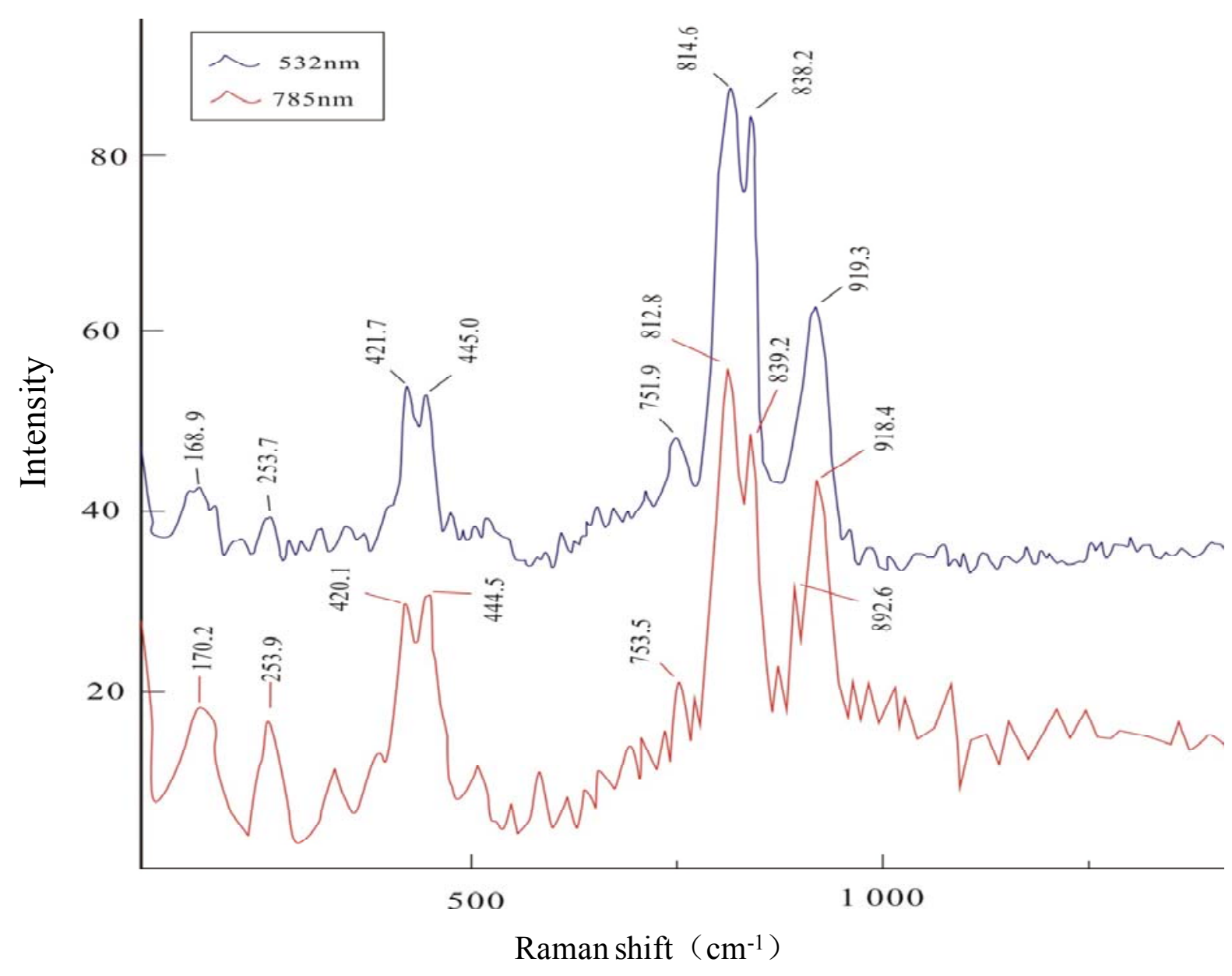

Fig 3 Raman spectrum of tengchongite from 100 to $1400 \mathrm{~cm}^{-1}$ region by $532 \mathrm{~nm}$ and 785 laser

\subsection{Infrared spectroscopy of tengchongite}

Infrared spectroscopy(IR) is an essential method for mineral

identification[15-20],especially as a complement to X-ray structural analysis in understanding the crystal chemistry of uranyl minerals. A lot of researches have reported uranyl minerals identification results by IR spectra[21-23]. The Infrared spectrum of tengchongite with in $640 \mathrm{~cm}^{-1}$ to $4000 \mathrm{~cm}^{-1}$ is shown in Figure 4 in reflection model. The IR analysis result of tengchongite is a bit different from the study of Chen et al.(1985)[4], i.e., there are mainly 3 absorption peaks and no hydroxyl $\left(\mathrm{OH}^{-1}\right)$ absorption band in Chen's work which are 3430 $\mathrm{cm}^{-1}, 1640 \mathrm{~cm}^{-1}$ and $920 \mathrm{~cm}^{-1}$, however, we determined more absorption bands such as 3100 $\mathrm{cm}^{-1}$ to $3600 \mathrm{~cm}^{-1}, 1647.5 \mathrm{~cm}^{-1}, 1432.4 \mathrm{~cm}^{-1}, 985.3 \mathrm{~cm}^{-1}, 905.6 \mathrm{~cm}^{-1}, 780.6 \mathrm{~cm}^{-1}$ and 644.1 $\mathrm{cm}^{-1}$. The broad band $3100 \mathrm{~cm}^{-1}$ to $3500 \mathrm{~cm}^{-1}$ which is centered at $3300 \mathrm{~cm}^{-1}$ is due to the stretching vibration of $\mathrm{H}_{2} \mathrm{O}$. The band at $1647.5 \mathrm{~cm}^{-1}$ is a consequence of the bend vibration of $\mathrm{H}_{2} \mathrm{O} . \mathrm{H}_{2} \mathrm{O}$ groups give bands in $1600-1650 \mathrm{~cm}^{-1}$ and $3100-3500 \mathrm{~cm}^{-1}(\mathrm{vOH})$, and the band at 
$1432.4 \mathrm{~cm}^{-1}$ is probably due to the stretching vibration hydroxyl $\left(\mathrm{OH}^{-1}\right)$, which indicates that there may be hydroxyl in tengchongite, and the original chemical formula of tenchongite needs to be modified. The band at $985 \mathrm{~cm}^{-1}$ was attributed to $v_{1}\left(\mathrm{MoO}_{2}\right)^{2+}$ stretching vibration and that at $780.6 \mathrm{~cm}^{-1}$ tov $_{3}\left(\mathrm{MoO}_{2}\right)^{2+}$. The band at $905.6 \mathrm{~cm}^{-1}$ was attributed to $v_{3}\left(\mathrm{UO}_{2}\right)^{2+}$ and that at $644.1 \mathrm{~cm}^{-1}$ tov $_{1}\left(\mathrm{UO}_{2}\right)^{2+}$.

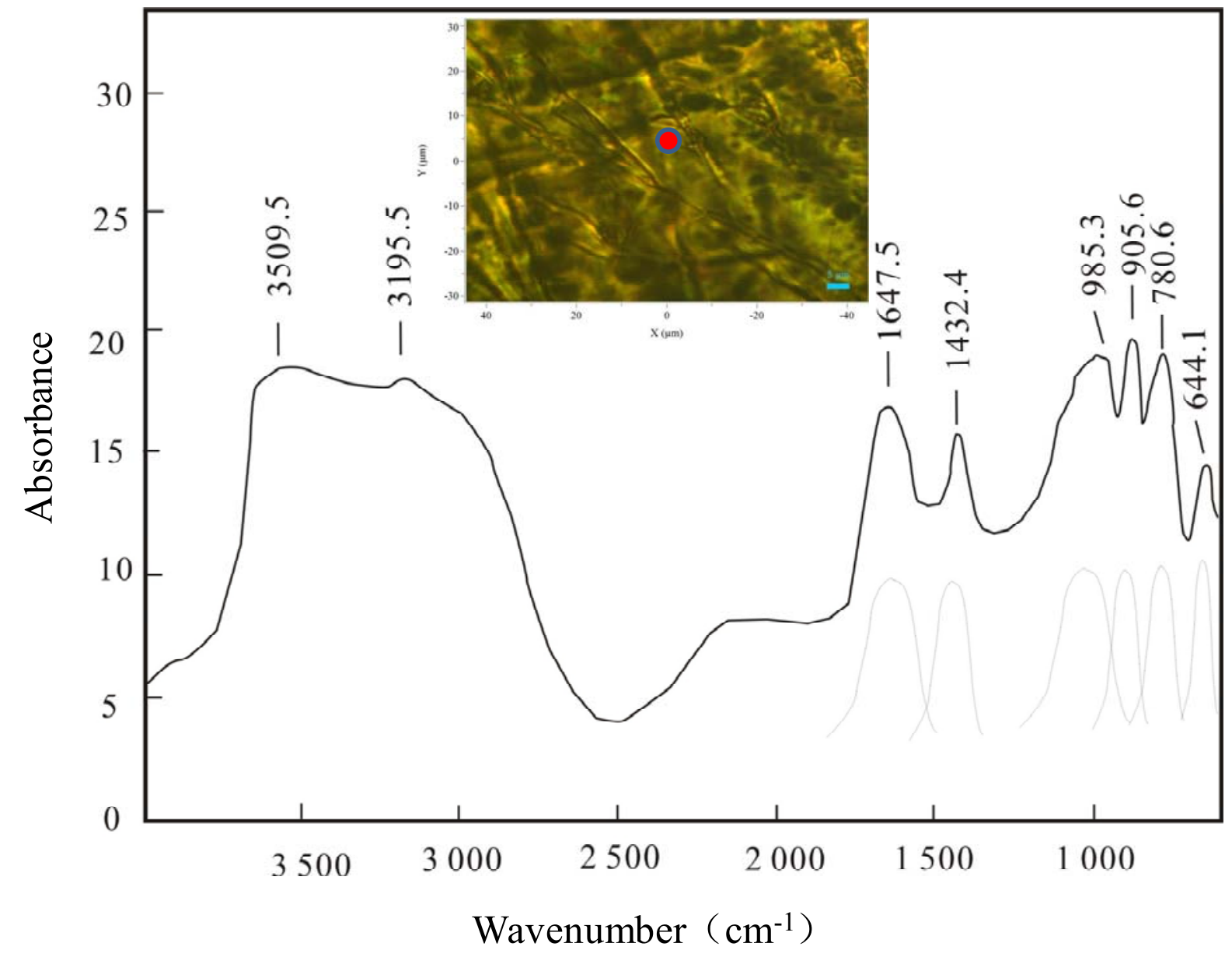

Figure 5 Infrared spectrum of tengchongite from $600 \mathrm{~cm}^{-1}$ to $4000 \mathrm{~cm}^{-1}$ region

\section{Conclusions}

(a) The Raman spectrum of tengchongite shows intense bands at $812 \mathrm{~cm}^{-1}$ and $839 \mathrm{~cm}^{-1}$ assigned to the $v_{1}$ symmetric stretching mode of $\left(\mathrm{UO}_{2}\right)^{2+}$ units . Raman band at $896 \mathrm{~cm}^{-1}$ is attributed to the $v_{3}\left(\mathrm{UO}_{2}\right)^{2+}$, Raman bands at 419 and $440 \mathrm{~cm}^{-1}$ are attributed to the $v_{2}\left(\mathrm{UO}_{2}\right)^{2+}$ in-plane bending modes. In infrared spectrum, intense bands at $644.1 \mathrm{~cm}^{-1}$ and $905.6 \mathrm{~cm}^{-1}$ are attributed to the symmetric stretching mode of the $\left(\mathrm{UO}_{2}\right)^{2+}$ units.

(b) Raman band at $919 \mathrm{~cm}^{-1}$ is assigned to $v_{1}\left(\mathrm{MoO}_{4}\right)^{2-}$ symmetric stretching vibration, The $v 3$ antisymmetric stretching mode of $\left(\mathrm{MoO}_{4}\right)^{2-}$ is observed at $752 \mathrm{~cm}^{-1}$. The bands at 419 $\mathrm{cm}^{-1}, 440 \mathrm{~cm}^{-1}, 254 \mathrm{~cm}^{-1}$ and $169 \mathrm{~cm}^{-1}$ are assigned to $v 2$ in-plane bending modes and $v_{4}$ out-of-plane bending modes of $\left(\mathrm{MO}_{4}\right)^{2-}$. The infrared band at $985 \mathrm{~cm}^{-1}$ is assigned to $v_{1}$ 
$\left(\mathrm{MoO}_{2}\right)^{2+}$ stretching vibration and that at $780.6 \mathrm{~cm}^{-1}$ to $v_{3}\left(\mathrm{MoO}_{2}\right)^{2+}$.

(c) The very broad infrared bands at 3100 3500 cm-1 are assigned to the stretching vibrations of water. $\mathrm{H}_{2} \mathrm{O}$ groups give bands in the regions $1600-1650 \mathrm{~cm}^{-1}\left(\delta \mathrm{H}_{2} \mathrm{O}\right)$ and $3100 \sim 3500 \mathrm{~cm}^{-1}(\mathrm{VOH})$, and the band at $1432.4 \mathrm{~cm}^{-1}$ is probably due to the stretching vibration hydroxyl $\left(\mathrm{OH}^{-1}\right)$, which indicates that there may be hydroxyl in tengchongite. The original chemical formula of tengchongite may be inaccurate, and further research should be studied.

\section{Reference}

[1] Cheng, Z.R;Luo, K.D;Zhang, Y; Gu, X.f; Tengchongite-a new uranyl molybdate uranium mineral.Science Bulletin.1985, 13, 1011-1015.

[2] Min, G.Y.The geological setting of Tengchongite and Yingjiangite.Yun nan Geology. 1994, 13(1),98-105

[3] Zhang, J.Y; Wang, A.Z,Li, X.Y; Zheng, Z.X; Li, J.Z;Uranium Minerals of China. 1995,271 272

[4] Peter C; Burns; Robert Finch(ED). Uranium:Mineralogy, Geochemistry and the Environment.1999,Mineralogical Society of America.p561

[5] HUANG, E; CHEN,C.H; HUANG, T; LIN, E.H; XU, J.A. Raman spectroscopic characteristics of Mg-Fe-Ca pyroxenes. American Mineralogist. 2000, 85,473-479

[6] Liu, J.B; Ye, kai; Cong,B.L; Mareyam, A,S; Fan,H.R. Co-exit inclusion in zircon from gneisses identified by laser raman micro spectrometer in ultra-high pressure zone of Dabie Mountains,China. Chinese Science Bulletin.2001, 46(22), 1912-1916

[7] Frost,R. L; Cejka, J; Ayoko, G. A; Dickfos, M.J. Raman spectroscopic study of the uranyl carbonate mineral voglite. Journal of RamanSpectroscopy.2008, 39(3), 374-379.

[8] Yang, Y.P; Zheng,H.F; Zhang,L.F. Determining pressure with daughter minerals fluid inclusion by Raman spectroscopy: sphalerite as an example. Acta Geologica Sinica.2009, 83(3), 628 632

[9] Konstantin,D; Litasov; Nikolay,M; Podgornykh. Raman spectroscopy of various phosphate minerals and occurrence of tuite in the Elga IIE iron meteorite. Journal of Raman Spectroscopy.2017, wileyonlinelibrary.com) ;DOI 10.1002/jrs.5119

[10] Biswajit, Mishra; Kamal, L.P; Pranjit, H; Sakthi, S.C. Nature and source of the ore-forming fluids associated with orogenic gold deposits in the Dharwar craton. Geoscience of Fronties,2018,9,715 726

[11] Kang,D; Wu, X,Guan, Y; Huang, S.X, Niu, J.J; Gao, J; Qin, S. High-pressure synchrotron X-ray diffraction and Raman spectroscopic study of plumbogummite. Chinese Physics B.2018,27(1),017402 017406

[12] Alessandro,C; Aldo, A; Caterina, R. Raman micro-spectroscopy identifies carbonaceous particles lying on the surface of crocidolite, amosite, and chrysotile Fibers. minerals,2018, 8, 249; doi: $10.3390 / \min 8060249$

[13] Chou, I.M.; Wang, A. Application of laser Raman micro-analyses to earth and planetary materials. Asian Earth Sci. 2017, 145, 309-333.

[14] Xi, S.C; Zhang, X; Luan, Z.D; Du,Z.F; Li, L.F; Liang,Z.W; Lian,C; Yan,Jun .Micro-Raman study of thermal transformations of sulfide and oxysalt minerals based on the heat induced by laser. Minerals 2019, 9, 751

[15] Hawthorne,F.C(Ed).Spectroscopic methods in mineralogy and geology. Reviews in 
Mineralogy.1988,18,698

[16] Farmer,V .C .Differing effects of particle size and shape in the infrared and Raman spectra of kaolinite. Clay Minerals .1998,33, 601-604

[17] Lane,M.D.Mid-infrared emission spectroscopy of sulfate and sulfate-bearing minerals. American Mineralogist.2007,92, 1-18

[18] Yang,X; Keppler,H; Dubrovinsky,L; Kurnosov.A In-situ infrared spectra of hydroxyl in wadsleyite and ringwoodite at high pressure and high temperature. American Mineralogist.2014,99, 724-729

[19] Du,G; Wang,K.Y;Lan,N; Wang, F.Y; Pan, Z.X. Application of IR/SEM and other modern instruments for mineral identification. Rock and Mineral Analysis.2014,33(5),625-633

[20] Turner,D.J; Rivard,B; Groat,L.A. Visible and short-wave infrared reflectance spectoscopy of selected REE-bearing silicate minerals. American Mineralogist.2018,103, 927-943

[21] Wilkins,W.B; Infrared spectroscopy in the mineralogical sciences of uranium ores.Neues Jb Miner Mh.1971,10,440-450

[22] Cejka,J; Urbance,Z. Secondary uranium minerals. Transaction of the Czechoslovak Academy of Science,Math Nature. History Series.1990, 100:p93

[23] Qiu, L.F; Ou, G.X; Zhang, M; Li, Q; Wu, D; Shang, C.J. Micro-area analysis of uranium minerals by Micro FT-IR spectrometry. ACTA MINERALOGICA SINICA.2016,36(1),43 47 